\title{
The Widening Divide in Business Turnover between Large and Small Urban Areas
}

\author{
By Jason P. Brown
}

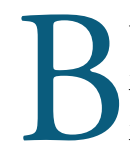

usiness turnover-the rate at which new firms enter the economy and old firms exit it — has been declining for at least 40 years in the United States. Declining business turnover is potentially problematic, because it may signal a drop in innovation and productivity growth. Economic theory suggests that business turnover can fuel economic growth by allowing new firms to replace older and potentially less efficient firms. Declining turnover may also signal a lower share of economic activity at new businesses, which historically have been a strong source of job growth. As a result, the country's economic fortune is likely to be intertwined with its rate of business turnover.

However, certain areas of the country may experience greater declines in business turnover than others. The U.S. economy has continued to transition from producing goods to providing services, with the share of gross domestic product from services increasing from nearly 60 percent to 80 percent over the past 50 years. Because much of the service sector is increasingly based on knowledge, idea exchange, and agglomeration, the economic base has shifted in a way that highly favors more populous areas. This transition to larger urban areas appears to have accelerated following the Great Recession.

Jason P. Brown is an assistant vice president and economist at the Federal Reserve Bank of Kansas City. Colton Tousey, a research associate at the bank, helped prepare the article. This article is on the bank's website at www.KansasCityFed.org 
In this article, I document recent trends in business turnover across metropolitan areas of various sizes and show that business turnover has declined much more sharply in small than in large urban areas. I also show that this gap widened in the years following the Great Recession. I then estimate a relationship between changes in business turnover and urban area size from 2000 through 2014 for over 900 metropolitan and micropolitan areas. I find that business turnover declined more for service-providing sectors than for goods-producing sectors, but the gap in business turnover between small and large urban areas widened more in the goods-producing sectors than the service-providing sectors. I also find that the level of business turnover was significantly higher in large and medium-sized metros relative to small metropolitan and micropolitan areas. This result supports previous findings of economic activity increasingly concentrating in the largest urban areas in the country (Glaeser 2011; Moretti 2012). Moreover, my results suggest the widening economic divide between small and large urban areas is unlikely to reverse course. Overall, shifts in both the composition of the economy and business turnover help explain some of the mechanisms behind the widening economic divide between small and large urban areas of the country.

Section I documents trends in business turnover in the United States and highlights how those trends vary across small, medium, and large metropolitan areas. Section II models potential factors related to the trends in metro area business turnover and discusses potential implications of the widening gap in urban area business turnover.

\section{Trends in Business Turnover in the United States}

Business turnover is a vital part of any economy. When new firms enter the economy, they may bring new ideas, products, and technologies. If these firms are more competitive, they may grow and replace less competitive firms over time. This process of new firms forcing out older, less efficient firms is often referred to as Schumpeter's theory of "creative destruction." Schumpeter maintained that the vitality of capitalist economies depends on the formation of new goods and services, new methods of production or transportation, new forms of industrial organization, and new product and input markets. Proponents of this theory view the turnover of businesses entering and exiting as important for innovation, economic productivity, and growth more broadly 


\section{Chart 1}

Business Turnover in the United States

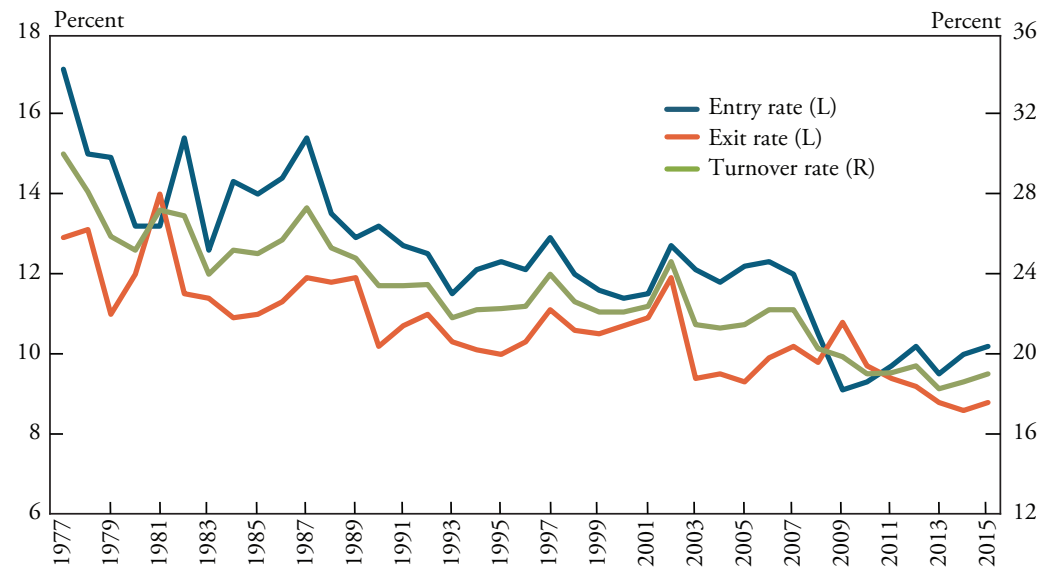

Sources: U.S. Census Bureau and author's calculations.

(Guzman and Stern 2016; Goldschlag and Perlman 2017; Casares and Khan 2016; Alon and others 2018).

However, business turnover in the United States has steadily declined over the past 40 years (Haltiwanger and others 2014; Decker and others 2016a). Chart 1 shows the rates of businesses entering and exiting the economy from 1977 to 2015 as well as the "turnover rate"the sum of the entry and exit rates-using information from the U.S. Census Bureau's Business Dynamics Statistics (BDS). ${ }^{1}$ The green line in Chart 1 shows that business turnover across all industries was 28.1 percent in 1977, meaning that 28 percent of total businesses entered or exited the economy in that year. By 2015, business turnover had dropped to 19 percent. Although both entry and exit rates declined over that period, the decline was larger in business entry: the entry rate declined by 40 percent, while the exit rate declined by 30 percent.

\section{Shift in industrial composition and implications for business turnover}

While business turnover declined, the U.S. economy continued to shift from producing goods to providing services. This shift in industrial composition led to a reallocation of workers and investment in the economy. But both the compositional shift and the subsequent reallocation likely varied across urban areas of different sizes. Goods-producing 


\section{Chart 2}

Business Turnover in Goods-Producing and Service-Providing Sectors

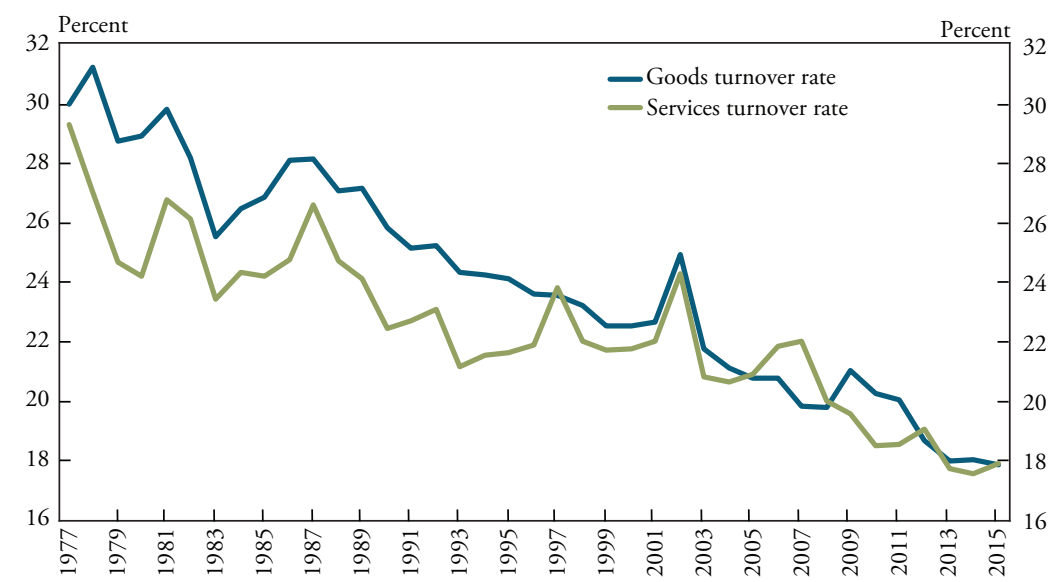

Sources: U.S. Census Bureau and author's calculations.

sectors, for example, often make up a higher share of economic activity in smaller urban areas (Henderson 1997). As a result, a shift away from goods-producing sectors may have dampened economic activity more in smaller urban areas than larger areas.

Measures of both employment and output reveal the shift in industrial composition. The share of private employment in goods-producing industries (manufacturing, construction, and natural resources and mining) as well as the share of real gross domestic product in these industries declined over time. The goods-producing share of employment declined from 34 percent in the late 1970s before stabilizing around 16 percent in 2010 (Bureau of Labor Statistics). Similarly, the goods-producing share of GDP fell from 27 percent in the late 1980s to about 20 percent from 2010 onward (Bureau of Economic Analysis).

Over the same period, business turnover declined in both goods-producing and service-providing sectors. Chart 2 shows that from 1977 to 2015, the business turnover rate declined 12.4 percentage points in goodsproducing sectors and 11.2 percentage points in service-providing sectors. Over most of that period, business turnover was lower in the service-providing sectors. Together, the differences in turnover between goods-producing and service-providing sectors - and the differences in industrial composition between small and large urban areas—-suggest changes in business turnover may differ across urban areas of different sizes. 


\section{Trends in business turnover across the urban size distribution}

To capture differences in business turnover across urban areas of various size, I use county-level tabulations of business turnover provided by the U.S. Census Bureau's Statistics of U.S. Businesses (SUSB). These data use the same source as the BDS but are processed with slightly different algorithms and are available at the county-by-industry level beginning in $1998 .{ }^{2}$ I use the SUSB county-level data to group counties into urban areas known as Core Based Statistical Areas (CBSAs). ${ }^{3}$ CBSAs are defined as micropolitan or metropolitan depending on the population of urbanized areas within each county and neighboring counties.

Using county-level population data allows me to show business turnover from the smallest to the largest urban areas in the country. I label CBSAs as micropolitan (fewer than 220,000 people), small metro (220,000 to $<1$ million people), medium metro ( 1 to $<4$ million people), or large metro ( 4 million or more people). Table 1 reports population summary statistics of the assigned groups measured in 2000 . The majority of the urban areas in the sample are micropolitan, with a population ranging from 13,000 to 214,000. Although the Census Bureau has no official definition of rural areas, many of these micropolitan areas could be considered rural in nature.

Business turnover in smaller urban areas historically has been lower than in larger areas, and the differences between them have grown larger over time. Chart 3 shows the business turnover rate by urban size from 1998 to $2014 .{ }^{4}$ The chart illustrates two key findings. First, the level of business turnover was lowest in micropolitan areas throughout the sample period. Second, the differences in turnover across urban areas were smaller earlier in the sample period and grew larger over time, especially in the post-Great Recession recovery from 2010 on. Medium and large metros saw similar declines in turnover, while the declines for small metro and micropolitan areas were more pronounced.

The gap between the smallest and largest urban areas persists even when accounting for differences in industrial composition. Chart 4 shows that average business turnover in goods-producing sectors was similar across urban areas in the late 1990s and early 2000s but began to separate and follow different trends during and following the Great Recession. By 2014, the differences across urban areas were much 


\section{Table 1}

Population Range of Urban Areas in 2000

\begin{tabular}{l|c|c|c|c}
\hline \multirow{2}{*}{ Urban area } & \multirow{2}{*}{ Number } & Minimum & Maximum & Median \\
\cline { 3 - 5 } & 734 & 12,949 & 213,967 & 54,637 \\
\hline Micropolitan & 134 & 222,407 & 972,501 & 387,899 \\
Small metro & 38 & $1,041,759$ & $3,277,022$ & $1,638,299$ \\
Medium metro & 11 & $4,135,875$ & $18,356,204$ & $4,740,056$ \\
Large metro & & &
\end{tabular}

Sources: U.S. Census Bureau and author's calculations.

\section{Chart 3}

Business Turnover by Urban Area Size

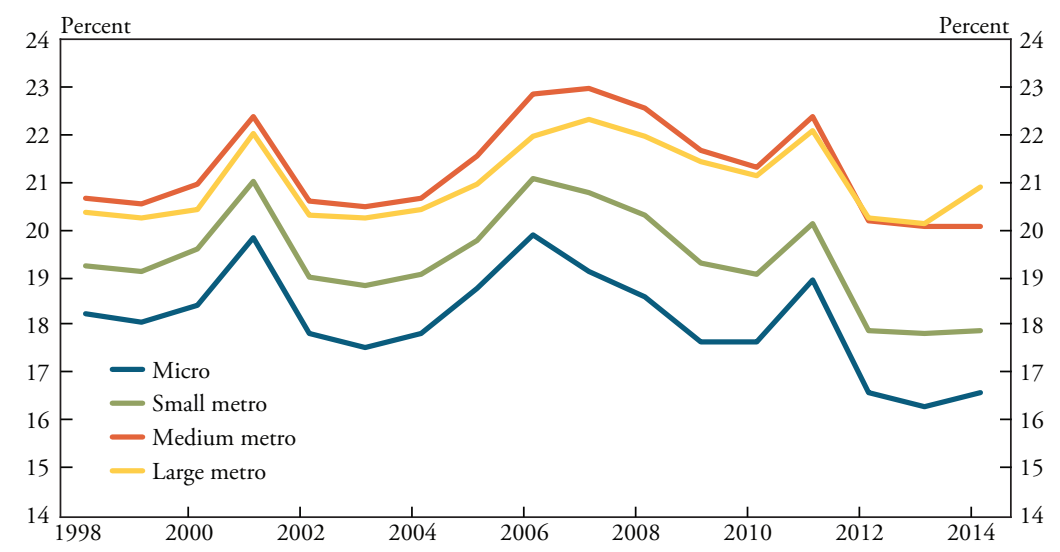

Sources: U.S. Census Bureau and author's calculations.

larger. The turnover rate remained lowest in micropolitan areas, while the rate actually increased in medium and large metros from 2000 to 2014. The trends illustrated in Chart 4 are somewhat surprising: although goods-producing sectors account for a smaller share of economic activity in large urban areas, business turnover in these sectors became significantly higher in large urban areas relative to small urban areas over time.

To confirm this surprising result, Chart 5 shows a "box-andwhisker" plot of the distribution of the share of goods-producing employment from 2000 to 2014 by urban area size. The average and median shares within CBSAs of each size are indicated by " $x$ " and the horizontal line inside of the blue box, respectively. The "whiskers" 


\section{Chart 4}

Business Turnover in Goods-Producing Sectors by Urban Area Size

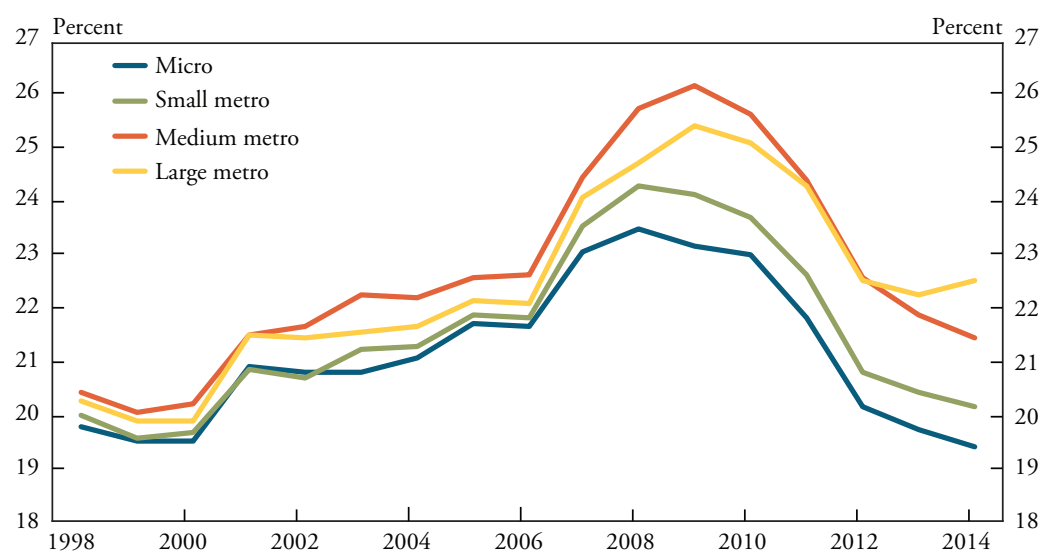

Sources: U.S. Census Bureau and author's calculations.

\section{Chart 5}

Goods-Producing Share of Employment by Urban Area Size, 2000 to 2014

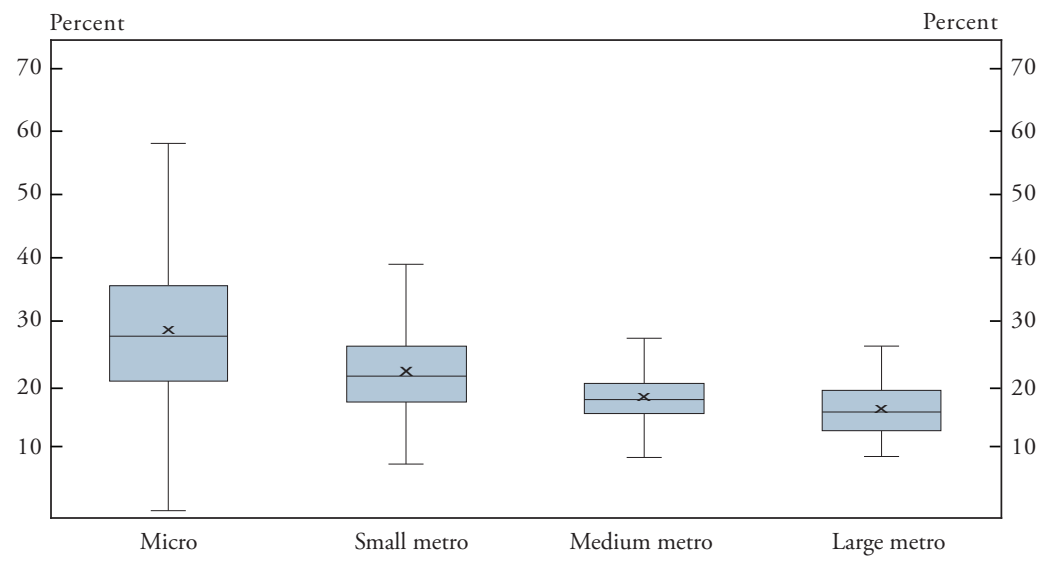

Notes: The mean and median are indicated by an " $x$ " and a horizontal line, respectively. The box represents the 25th and 75th percentile of the distribution of each urban area.

Sources: Bureau of Labor Statistics and author's calculations. 
extending above and below the box show the total percentile range of the goods-producing share in all metros of a given size, while the blue box itself displays the 25 th to 75 th percentile range in which most observations are clustered, also referred to as the "interquartile range." The chart provides a clear illustration of how the share of employment in the goods-producing sector decreases as the size of a metro area increases. Although the goods-producing sector makes up a smaller share of economic activity in large CBSAs, it appears to be more dynamic (that is, it has higher business turnover) in larger urban areas than in smaller ones.

The manufacturing sector exemplifies the declining trends in business turnover within goods-producing sectors. Several studies have investigated business turnover in manufacturing from many different vantage points and over many different periods (Dunne and others 2005; Bernard and Jensen 2007; Brown and others 2013). However, these studies have not examined trends by urban area size. Chart 6 shows the business turnover of manufacturing firms from 1998 to 2014 . For both micropolitan and small metro areas, average turnover declined by almost 2 percentage points (a 14 percent reduction). Although turnover also declined steadily in medium metros, the decline was not as large.

Business turnover in the service-providing sectors trended down across urban areas, except in large metros. Chart 7 shows that business turnover in the service-providing sectors differed more dramatically across urban areas of different size than turnover in the goods-producing sectors (for comparison, see Chart 5). Moreover, the differences in turnover across urban areas grew larger over time. By 2014, business turnover in service-providing sectors was highest in large metros. The largest decline in turnover during the sample period occurred in micropolitan areas, followed by small and medium metros.

The retail trade sector experienced some of the largest changes in business turnover among service-providing sectors. The average business turnover rate for retail trade declined 2 to 3 percentage points over the sample period for all urban areas except large metros, where the rate declined only 0.1 percentage point (Chart 8). The largest decline in both absolute and relative terms occurred in micropolitan areas, where business turnover in the retail sector declined by 2.7 percentage points, a 17 percent reduction. While business turnover was virtually the same 


\section{Chart 6}

Manufacturing Business Turnover by Urban Area Size

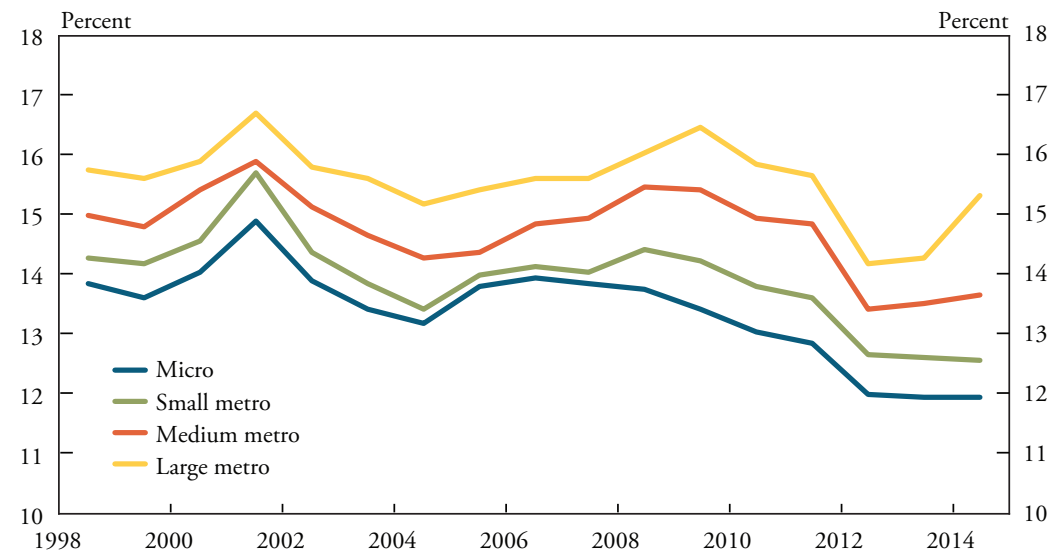

Sources: U.S. Census Bureau and author's calculations.

\section{Chart 7}

Business Turnover in Service-Providing Sectors by Urban Area Size

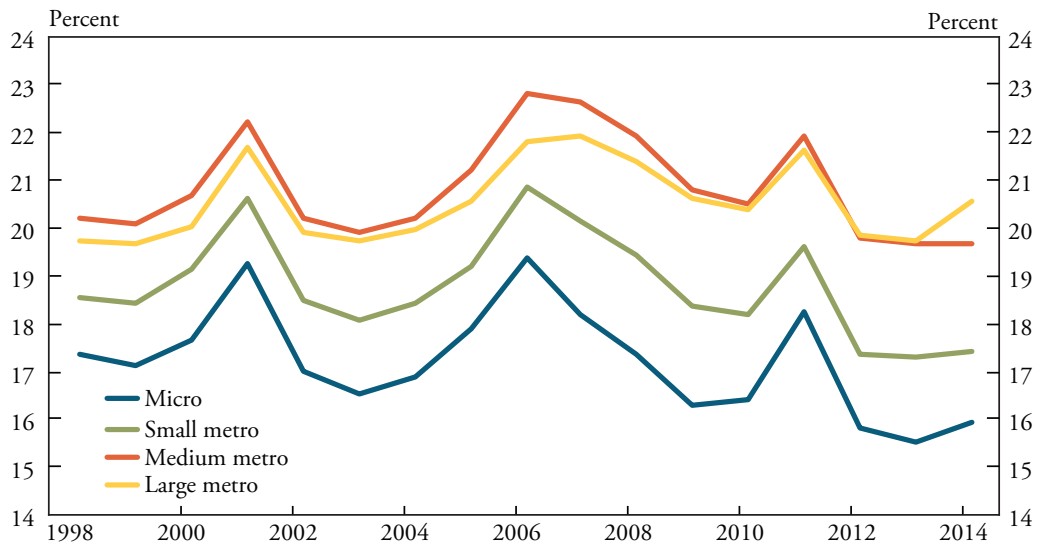

Sources: U.S. Census Bureau and author's calculations. 


\section{Chart 8}

Retail Sector Business Turnover by Urban Area Size

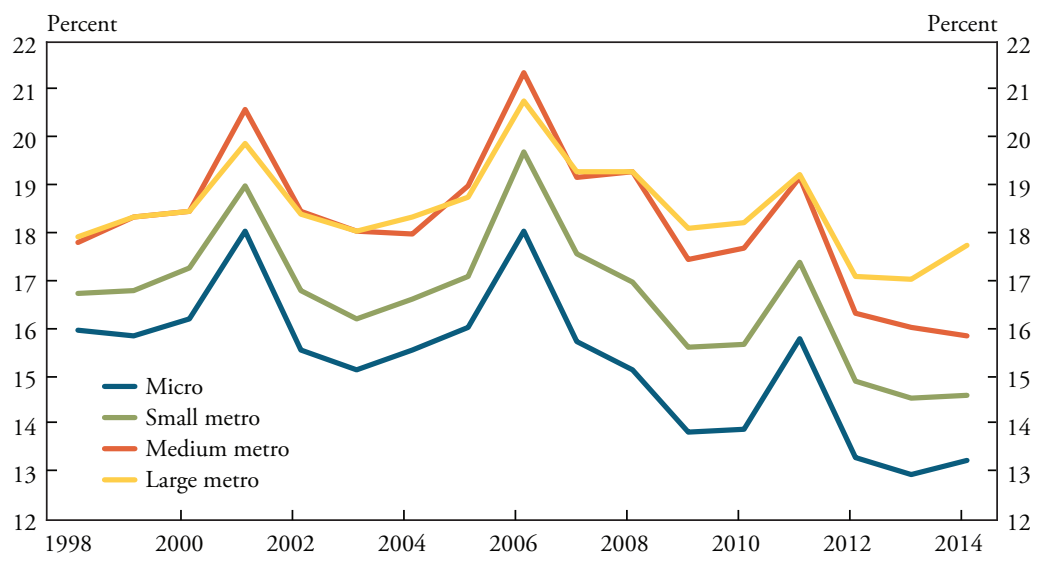

Sources: U.S. Census Bureau and author's calculations.

in medium and large metros throughout most of the sample period, the rates diverged beginning in 2012. Turnover in large metros stabilized, but turnover in medium metros continued to fall.

Overall, both goods-producing and service-providing sectors experienced declining business turnover with increasingly larger declines in less populous areas. However, there were a few exceptions to this declining trend. Business turnover increased in the construction sector, especially in medium and large metros, from 1998 to 2014. In the transportation sector, business turnover increased in large metros and fluctuated in medium metros from 2010 on. And in the professional and business services sector, business turnover was flat in medium metros but increased in large metro areas from 2010 through 2014.

Despite these exceptions, the gap in business turnover between the smallest and largest urban areas increased in every one of the major industry sectors from 1998 to 2014. Chart 9 shows these gaps across industries, calculated by subtracting the percentage point difference in business turnover between large metro and micropolitan areas in 1998 from the percentage point difference in 2014. Even in sectors that make up a larger share of economic activity in micropolitan areas, especially mining and manufacturing, the gap between business turnover in micropolitan areas versus large metros grew wider. 


\section{Chart 9}

Differences in Business Turnover between Large Metros and Micropolitan Areas Increased from 1998 to 2014

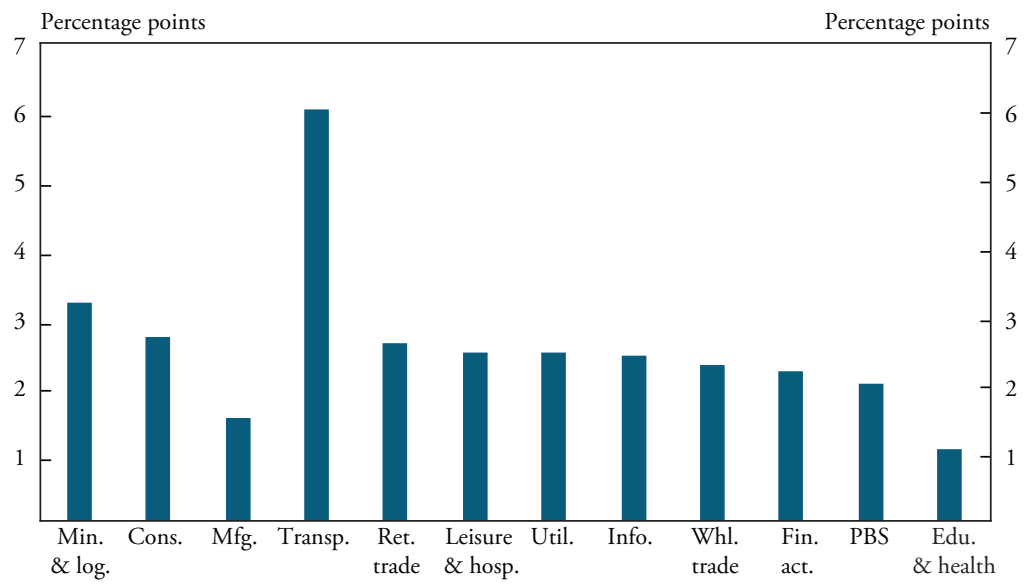

Sources: U.S. Census Bureau and author's calculations.

\section{Potential Factors Related to Differences in Urban Area Business Turnover}

The descriptive analysis of business turnover paints a compelling picture of the trends across urban areas: business turnover has declined most in smaller urban areas and is generally lower in these areas relative to larger metros. However, this picture does not reveal whether these trends are simply due to differences in industry composition in small versus large urban areas, or whether these trends are the result of inherent advantages to increased urban size.

To test these potential explanations, I use a panel regression model of urban area business turnover rates from 2000 to 2014. I find that the overall trend in business turnover is negative. However, even after controlling for industry composition, turnover is significantly higher in small, medium, and large urban areas than in micropolitan areas. Given the existing research on geographical differences in growth across small versus large urban areas, it is unclear what would or even could reverse these trends. 


\section{Potential factors explaining differences in business turnover}

Prior research on business turnover has tended to focus on either the decisions of firms to enter and exit the economy or possible differences across areas. For example, several researchers have documented factors that explain entry and exit decisions at the firm level (Dixit 1989; Hopenhayn 1992; Pakes and Ericson 1998; Dunne and others 2005; Bernard and Jensen 2007). Fewer researchers have documented why the decline in U.S. business turnover has occurred, although it is an emerging area of study. Decker and others (2016a), for example, highlight the role of the shifting sectoral composition in the U.S. economy, especially movement away from manufacturing toward services. And Decker and others (2016b) suggest the lack of young high-growth firms as a partial explanation.

A number of reasons have been suggested for why business turnover varies by region. Hathaway and Litan (2014) find that population growth across metropolitan areas is positively correlated with the variation in new firm formation. Guzman and Stern (2016) suggest differences in entrepreneurship as a potential explanation, showing that the quality of entrepreneurs varies across the United States as measured by innovation through patents.

Using available data on some of the factors highlighted in previous research, I estimate a model for business turnover trends for over 900 urban areas from 2000 to 2014. Specifically, I use a fixed effects panel model to estimate the business turnover rate $y$ in urban area $i$ in year $t$. The model is expressed by:

$$
y_{i t}=\gamma_{i}+\tau \cdot \text { trend }+\theta_{t} \cdot \text { year }_{t}+\beta X_{i t}+\tau_{j} \sum_{j}^{3} \text { trend }_{j}+\varepsilon_{i t}
$$

where $\gamma_{i}$ captures urban area time-invariant factors; trend denotes the average time trend in business turnover; year ${ }_{t}$ controls for individual year fixed effects, which allow for business turnover to deviate from the trend due to the business cycle; $X_{i t}$ captures industry composition; trend $_{j}\left(=\right.$ urban size $j_{j}$ year $)$ captures differences in the trend of business turnover by urban area size ( $j=$ small, medium, and large as previously defined); and $\varepsilon$ is an error term. I measure industry composition with the goods-producing share of total private employment in each urban area using county-level employment data from the Bureau of Labor 
Statistics's Quarterly Census of Employment and Wages. The coefficient $\tau$ on the time trend is expected to be negative given the observed overall decline in business turnover. The coefficients $\tau_{j}$, which measure the differences in the business turnover trend by urban area size, are expected to be positive, as they measure the differences between small, medium, and large metros relative to micropolitan areas.

The results in Table 2 confirm the findings in the previous section: business turnover declined everywhere, but more so among micropolitan and small urban areas. As expected, the coefficient on the time trend $(-0.14)$ is negative and statistically significant, indicating that on average, business turnover declined by 0.14 percentage point each year from 2000 to 2014 , a cumulative decline of 2.1 percentage points. The coefficients for urban area size are calculated using micropolitan areas as the reference category-in other words, the coefficients test whether small, medium, or large urban areas had different trends in business turnover relative to micropolitan areas. The results show that the trends in small, medium, and large metro areas differ significantly from the trend in micropolitan areas. Specifically, the coefficients indicate that the difference in turnover between micropolitan areas and small, medium, and large urban areas increased by $0.02,0.10$, and 0.13 percentage point, respectively, each year. By 2014, those differences accumulate to a $0.3(0.02 \times 15$ years $)$ percentage point higher rate of business turnover in small urban areas, a $1.5(0.10 \times 15$ years $)$ percentage point higher rate of business turnover in medium metros, and a $1.95(0.13 \times 15$ years) percentage point higher rate of business turnover in large metros compared with micropolitan areas. Finally, the coefficient for the goods share of total private employment is positive and significant, indicating that areas with a higher share of goods-producing employment tend to experience higher turnover, consistent with the data in Chart 4.

Given the compositional shift in the U.S. economy and differences in business turnover between goods-producing and service-providing sectors, I next explore these differences across urban areas. Table 3 shows the results from a similar model that estimates business turnover separately for the goods-producing and service-providing sectors. Even though I consider the sectors separately, I keep the goods-producing share of employment in the model because the industrial composition could influence business turnover in both goods-producing and 


\section{Table 2}

Business Turnover Trends by Urban Area

\begin{tabular}{|c|c|c|}
\hline Variable & Coefficient & Robust standard errors \\
\hline trend & $-0.14^{* * *}$ & 0.01 \\
\hline goods share & $0.04^{* *}$ & 0.02 \\
\hline trend small metro & $0.02^{* *}$ & 0.01 \\
\hline trend medium metro & $0.10^{* * *}$ & 0.01 \\
\hline trend large metro & $0.13^{* * *}$ & 0.01 \\
\hline y2001 & $1.51^{* * *}$ & 0.06 \\
\hline y2002 & $-0.30^{* * *}$ & 0.06 \\
\hline y2003 & $-0.46^{* * *}$ & 0.06 \\
\hline y2004 & -0.06 & 0.06 \\
\hline y2005 & $0.94^{* * *}$ & 0.06 \\
\hline y2006 & $2.19^{* * *}$ & 0.06 \\
\hline y2007 & $1.64^{* * *}$ & 0.06 \\
\hline y2008 & $1.14^{* * *}$ & 0.07 \\
\hline y2009 & $0.41^{* * *}$ & 0.07 \\
\hline y2010 & $0.62^{* * *}$ & 0.08 \\
\hline y2011 & $1.99^{* * *}$ & 0.07 \\
\hline y2012 & $-0.22^{* * *}$ & 0.06 \\
\hline y2013 & $-0.33^{* * *}$ & 0.06 \\
\hline Adjusted $\mathrm{R}^{2}$ & 0.39 & \\
\hline$N=13,743$ & & \\
\hline \multicolumn{3}{|c|}{$\begin{array}{l}\text { * Significant at the } 10 \text { percent level } \\
\text { ** Significant at the } 5 \text { percent level } \\
\text { N** Significant at the } 1 \text { percent level } \\
\text { Notes: Standard errors are clustered at the CBSA level. Fixed effects are included in the regression. } \\
\text { Source: Author's calculations. }\end{array}$} \\
\hline
\end{tabular}

service providing sectors. The results show that over the 2000-14 period, the trend in business turnover declined more in service-providing sectors $(-0.13$ percentage point per year) than in goods-producing sectors $(-0.03$ percentage point per year). The coefficient on the goods share of total private employment is not statistically different across the two industry categories. However, the business turnover trend differs noticeably within these categories by urban size. Although turnover is lower in goods-producing sectors overall, the trend in small, medium, 


\section{Table 3}

Goods-Producing versus Service-Providing Business Turnover Trends by Urban Area

\begin{tabular}{|c|c|c|c|c|}
\hline \multirow[b]{2}{*}{ Variable } & \multicolumn{2}{|c|}{ Goods-producing sectors } & \multicolumn{2}{|c|}{ Service-providing sectors } \\
\hline & Coefficient & Robust standard errors & Coefficient & Robust standard errors \\
\hline trend & -0.03 & 0.02 & $-0.13^{* * *}$ & 0.01 \\
\hline goods share & $0.06^{* *}$ & 0.03 & $0.03^{* *}$ & 0.02 \\
\hline trend small metro & $0.08^{* * *}$ & 0.02 & $0.02^{* *}$ & 0.01 \\
\hline trend medium metro & $0.17^{* * *}$ & 0.02 & $0.09^{* * *}$ & 0.01 \\
\hline trend large metro & $0.17^{* * *}$ & 0.02 & $0.09^{* * *}$ & 0.01 \\
\hline y2001 & $1.40^{* * *}$ & 0.13 & $1.63^{* * *}$ & 0.06 \\
\hline y2002 & $1.19^{* * *}$ & 0.13 & $-0.41^{* * *}$ & 0.06 \\
\hline y2003 & $1.29^{* * *}$ & 0.14 & $-0.72^{* * *}$ & 0.06 \\
\hline y2004 & $1.43^{* * *}$ & 0.14 & $-0.28^{* * *}$ & 0.06 \\
\hline y2005 & $2.01^{* * *}$ & 0.13 & $0.81^{* * *}$ & 0.06 \\
\hline y2006 & $1.88^{* * *}$ & 0.13 & $2.40^{* * *}$ & 0.06 \\
\hline y2007 & $3.35^{* * *}$ & 0.14 & $1.43^{* * *}$ & 0.06 \\
\hline y2008 & $3.54^{* * *}$ & 0.14 & $0.74^{* * *}$ & 0.06 \\
\hline y2009 & $3.60^{* * *}$ & 0.16 & $-0.17^{* *}$ & 0.07 \\
\hline y2010 & $3.54^{* * *}$ & 0.16 & 0.10 & 0.08 \\
\hline y2011 & $2.36^{* * *}$ & 0.16 & $1.96^{* * *}$ & 0.07 \\
\hline y2012 & $0.76^{* * *}$ & 0.15 & $-0.29^{* * *}$ & 0.06 \\
\hline y2013 & $0.46^{* * *}$ & 0.14 & $-0.42^{* * *}$ & 0.06 \\
\hline $\begin{array}{l}\text { Adjusted } \mathrm{R}^{2} \\
\mathrm{~N}=13,743\end{array}$ & 0.13 & & 0.41 & \\
\hline $\begin{array}{l}\text { * Significant at the } \\
\text { ** Significant at the } \\
\text { *** Significant at the } \\
\text { Notes: Standard errors } \\
\text { Source: Author's calcul }\end{array}$ & $\begin{array}{l}\text { ercent level } \\
\text { rcent level } \\
\text { rcent level } \\
\text { ustered at the } \\
\text { s. }\end{array}$ & SA level. Fixed effects & cluded in th & gression. \\
\hline
\end{tabular}

and large metros is significantly higher than in micropolitan areas. The coefficient on the trends for medium and large metros is the same (0.17), indicating that medium and large metros had a cumulative 2.6 $(0.17 \times 15$ years $)$ percentage point higher turnover rate relative to micropolitan areas over the period. In service-providing sectors, turnover was also significantly higher in small, medium, and large metros than in micropolitan areas, but to a lesser extent. 
Potential implications of a widening gap in urban area business turnover

My results show significant differences in business turnover trends across urban areas. Turnover was significantly higher in larger urban areas than in small urban areas, although the differences at first pass may not seem large. However, because of the self-sustaining nature of economic development, urban areas that are similar initially can become very different over time. As Moretti (2012) demonstrates, small differences can become magnified: areas with "winners tend to become stronger and stronger, as innovative firms and innovative workers keep clustering there, while losers tend to lose further ground" (p. 79).

The implications for future growth in small and large urban areas are striking. Several recent papers note a link between declining business turnover and the slowdown in aggregate productivity in the U.S. economy (Decker and others 2017; Alon and others 2018). Slower productivity growth is associated with slower economic growth more broadly. Casares and Khan (2016) show that states with a sharper decline in firm entry rates from 1987 to 2013 also saw slower rates of economic growth. Conversely, states with higher co-movement of entry and exit had faster growth. If the trend of ever larger differences in business turnover across urban areas continues, micropolitan and small metro areas will likely continue to grow more slowly than large urban areas.

The different trends in business turnover across urban areas may also be linked to innovation. One measure of innovation is the number of utility patents, which are issued for new inventions (see, for example, Goldschlag and Perlman 2017). The U.S. Patent and Trademark Office tabulates counts of granted utility patents in each year, which I use to construct measures of U.S. granted utility patents per 100,000 people by urban area. The box plot chart in Chart 10 shows that even when normalizing patents by population, the mean $(x)$ and median (horizontal line) number of patents increases across the urban size distribution from micropolitan to large metro areas. Although the mean number of patents per 100,000 people is similar in medium and large metros, the box plot shows that the number of patents is higher in large metro areas.

Whether patents lead to higher business turnover or higher business turnover leads to more patents, however, is unclear. Since patents are a measure of innovation, areas with more innovation may attract more innovative workers and firms, leading to higher business turnover 
Chart 10

Patents by Urban Area Size, 2000-14

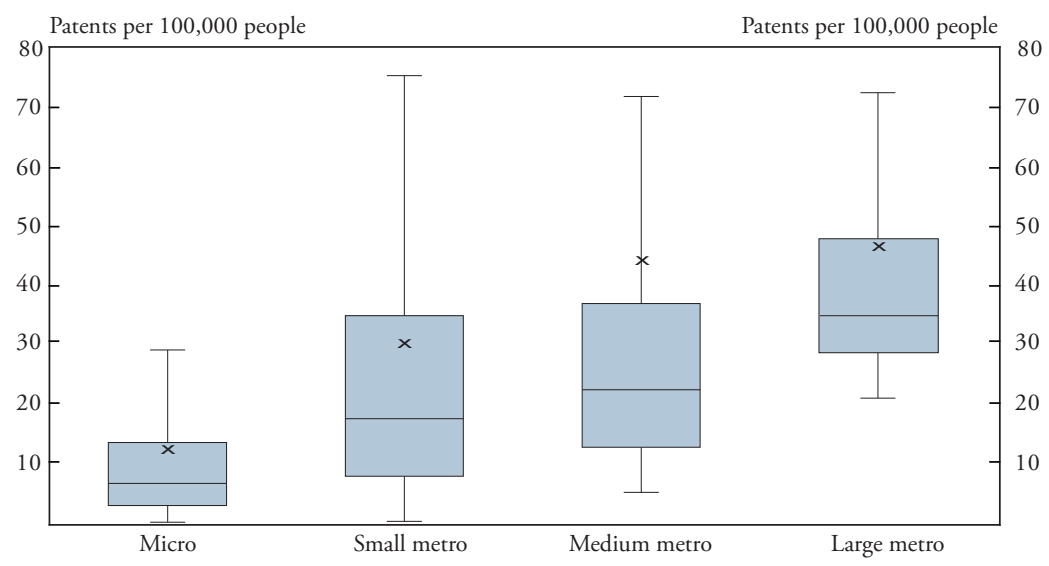

Notes: The mean and median are indicated by " $x$ " and horizontal line, respectively. The box represents the 25 th and 75 th percentile of the distribution of each urban area.

Sources: U.S. Patent and Trade Office, U.S. Census Bureau, and author's calculations.

as less innovative firms are pushed out (Hathaway and Litan 2014b). This explanation would be consistent with "winning" areas becoming economically stronger and stronger, as innovative firms and innovative workers increasingly cluster in larger urban areas.

\section{Conclusion}

U.S. business turnover has declined dramatically over the past several decades, while the economy's industrial composition has increasingly shifted from goods to services. But this trend has not taken hold in the same way across urban areas of different size. Business turnover has almost always been lower in micropolitan areas than in larger metro areas. However, since the Great Recession, the decline in business turnover has been more pronounced in micropolitan areas regardless of industry, whether goods-producing or service-providing. Moreover, the difference in business turnover between small and large urban areas has increased.

The exact reasons for the decline in business turnover are still mostly unknown, though it remains an active area of research. It is unclear, however, what would or even could reverse this trend-or shrink the gap between the trends in smaller and larger urban areas. Given their 
lower levels of business turnover, micropolitan and small urban areas may be at risk of becoming more static and less productive than larger urban areas. If the gap between the turnover rates of small and large urban areas continues to widen, the gap between their economic fortunes may widen as well. 


\section{Endnotes}

${ }^{1}$ The BDS data are annual measures of business dynamics compiled from the Longitudinal Business Database, which tracks firms over time based on employment records.

${ }^{2}$ Business turnover rates from the BDS and SUSB in a given year are not exactly the same. Both the BDS and SUSB data use the Business Register. However, the Longitudinal Business Database (LBD) used in the BDS also pulls information from other censuses and surveys. The LBD also uses different algorithms to deal with reorganization of firms.

${ }^{3}$ The 2003 CBSA definitions were used to construct urban area measures of business turnover. Metropolitan statistical areas have at least one urbanized area of 50,000 people or more plus adjacent territory that has a high degree of social and economic integration with the core as measured by commuting ties. Micropolitan statistical areas have at least one urban cluster of at least 10,000 but fewer than 50,000 people plus adjacent territory that has a high degree of social and economic integration with the core as measured by commuting ties.

${ }^{4}$ Business turnover was only available from the U.S. Census Bureau at the county-by-industry level through 2014. 


\section{References}

Alon, Titan, David Berger, Robert Dent, and Benjamin Pugsley. 2018. "Older and Slower: The Startup Deficit's Lasting Effects on Aggregate Productivity." Journal of Monetary Economics, vol. 93, pp. 68-85. Available at https://doi. org/10.1016/j.jmoneco.2017.10.004

Bernard, Andrew B., and J. Bradford Jensen. 2007. "Firm Structure, Multinationals, and Manufacturing Plant Deaths." Review of Economics and Statistics, vol. 89, pp. 193-204. Available at https://doi.org/10.1162/rest.89.2.193

Brown, Jason P., Dayton M. Lambert, and Raymond J.G.M. Florax. 2013. "The Birth, Death, and Persistence of Firms: Creative Destruction and the Spatial Distribution of U.S. Manufacturing Establishments, 2000-2006." Economic Geography, vol. 89, no. 3, pp. 203-226. Available at https://doi.org/10.1111/ ecge. 12014

Casares, Miguel, and Hashmat Khan. 2016. "Business Dynamism and Economic Growth: U.S. Regional Evidence.” International Review of Entrepreneurship, vol. 14, no. 4, pp. 423-445.

Decker, Ryan A., John Haltiwanger, Ron S. Jarmin, and Javier Miranda. 2017. "Declining Dynamism, Allocative Efficiency, and the Productivity Slowdown." American Economic Review, vol. 107, no. 5, pp. 322-326. Available at https://doi.org/10.1257/aer.p20171020

Decker, Ryan A., John Haltiwanger, Ron S. Jarmin, and Javier Miranda. 2016a. "Declining Business Dynamism: What We Know and the Way Forward." American Economic Review: Papers \& Proceedings, vol. 106, no. 5, pp. 203207. Available at https://doi.org/10.1257/aer.p20161050

Decker, Ryan A., John Haltiwanger, Ron S. Jarmin, and Javier Miranda. 2016b. "Where Has All the Skewness Gone? The Decline in High-Growth (Young) Firms in the U.S." European Economic Review, vol. 86, pp. 4-23. Available at https://doi.org/10.1016/j.euroecorev.2015.12.013

Dixit, Avinash. 1989. "Entry and Exit Decisions under Uncertainty." Journal of Political Economy, vol. 97, pp. 620-638. Available at https://doi. org/10.1086/261619

Dunne, Timothy, Shawn D. Klimek, and Mark J. Roberts. 2005. "Exit from Regional Manufacturing Markets: The Role of Entrant Experience." International Journal of Industrial Organization, vol. 23, pp. 399-421. Available at https://doi.org/10.1016/j.ijindorg.2005.01.011

Glaeser, Edward. 2011. Triumph of the City. New York: Penguin Press.

Goldschlag, Nathan, and Elisabeth Perlman. 2017. "Business Dynamic Statistics of Innovative Firms.” CES Working Paper no. 17-72, U.S. Census Bureau.

Haltiwanger, John, Ian Hathway, and Javier Miranda. 2014. "Declining Business Dynamism in the U.S. High-Technology Sector." The Kauffman Foundation. Available at https://doi.org/10.2139/ssrn.2397310

Hathaway, Ian, and Robert E. Litan. 2014. "What's Driving the Decline in the Firm Formation Rate? A Partial Explanation.” The Brookings Institution, November.

Henderson, Vernon. 1997. "Medium Size Cities." Regional Science and Urban Economics, vol. 27, no. 6, pp. 583-612. Available at https://doi.org/10.1016/ S0166-0462(96)02169-2 
Hopenhayn, Hugo. A. 1992. "Entry, Exit, and Firm Dynamics in Long Run Equilibrium.” Econometrica, vol. 60, no. 5, pp.1127-1150. Available at http://doi. org/10.2307/2951541

Moretti, Enrico. 2012. The New Geography of Jobs. Houghton Mifflin Harcourt.

Pakes, Ariel, and Richard Ericson. 1998. "Empirical Implications of Alternative Models of Firm Dynamics." Journal of Economic Theory, vol. 79, pp. 1-46. Available at https://doi.org/10.1006/jeth.1997.2358 